\title{
Health behavior modification after electron beam computed tomography and physician consultation
}

\author{
Jennifer Schwartz • Mathew Allison • \\ C. Michael Wright
}

Received: May 9, 2010/ Accepted: August 25, 2010/Published online: September 21, 2010

(C) The Author(s) 2010. This article is published with open access at Springerlink.com

\begin{abstract}
This study aimed to determine whether participants reported altering health behaviors (physical activity, diet, and alcohol consumption) after seeing results from an electron-beam computed tomography (EBCT) scan for coronary artery calcium and reviewing these results with a physician. Clinicians attempt to motivate patients to control cardiovascular risk factors by adopting healthy behaviors and reducing harmful actions. Asymptomatic patients $(\mathrm{N}=510)$ were evaluated by EBCT for the extent of coronary artery calcium. Information pertaining to demographics, health history, and lifestyle/health behaviors was obtained from each participant at the time of the EBCT scan. Patients were given their numerical calcium score, shown images of their coronary arteries, and counseled by a physician for lifestyle and medical risk modification based on their coronary artery calcium score. Approximately 6 years after the scan, participants completed a follow-up questionnaire related to lifestyle modifications. In multivariable analysis, the presence and extent of coronary artery calcium was significantly associated with beneficial health behavior modifications. Specifically, the greater a patient's coronary artery calcium score, the more likely they were to report increasing exercise (odds ratio $=1.34, P=0.02$ ), changing diet (odds ratio $=1.40$, $P<0.01$ ), and changing alcohol intake (odds ratio $=1.46$, $P=0.05$ ). This study suggests that seeing and being counseled on the presence and extent of coronary artery calcium is significantly associated with behavior change.
\end{abstract}

J. Schwartz $(\bowtie) \cdot$ M. Allison · C. M. Wright

Division of Preventive Medicine, University of California,

San Diego School of Medicine, 8950 Villa La Jolla Drive,

Suite A206, La Jolla, CA 92037, USA

e-mail: schwartj@rohan.sdsu.edu
Keywords Health behavior - Physical activity . Nutrition $\cdot$ Coronary artery calcium $\cdot$ Imaging

\section{Introduction}

Altering lifestyle patterns to reduce risk for cardiovascular disease is a challenging yet potentially rewarding strategy. The INTERHEART study demonstrated that optimizing nine modifiable risk factors could reduce risk for a first heart attack by over $90 \%$ (Yusuf et al. 2004). Recent data shows that only $15 \%$ of Americans over age 18 engage in $30 \mathrm{~min}$ of moderate activity five or more days per week (Klein et al. 2002). However, $65 \%$ of Americans are overweight or obese, while only $11 \%$ of Americans meet the USDA guidelines for fruit and vegetable intake (Klein et al. 2002).

Coronary artery calcium (CAC) as measured by computed tomography (CT) scanning of the heart is an accurate measure of coronary atherosclerosis. Moreover, the 2009 American Heart Association Heart Disease and Stroke Statistics 2009 Update states "CAC is a measure of the burden of atherosclerosis in the heart arteries." The Update also cites data from the NHLBI-sponsored Multiethnic Study of Atherosclerosis (MESA): "those with CAC scores greater than 100 were 7-10 times more likely to experience a coronary event than those without CAC" (Detrano et al. 2008).

A handful of studies have examined the effects of CT scanning on behavior change. For example, LaBounty et al. (2009) showed that greater severity of coronary artery disease (CAD), as revealed via coronary computed tomographic angiography, was significantly correlated with enhanced control of CAD risk factors such as dyslipidemia and hypertension among 208 patients with symptoms suggestive of angina but free of established CAD. An earlier study, reported by Wong et al. (1996), found that 
adults with the highest CAC scores were most likely to report losing weight, decreasing dietary fat, increasing vitamin $\mathrm{E}$ intake, and beginning use of aspirin, cholesterollowering therapy, and blood pressure medication 1 year after receiving EBCT scan results. A third study, by Orakzai et al. (2008), showed that patients with higher calcium scores were more likely to initiate beneficial dietary changes, exercise, and increased aspirin use. In a fourth study, Kalia et al. (2006) showed that visualization of coronary calcium on EBCT scans was associated with increased adherence to and utilization of statin therapy. Similarly, in the 6-year follow-up of the Prospective Army Coronary Calcium (PACC) Project, Taylor et al. (2008) showed that statin and aspirin use was significantly greater among participants with coronary calcification.

In this paper, we present data obtained at a Universityaffiliated disease prevention clinic. Patients underwent CAC scoring and Framingham risk assessment followed by a 15-30 min consultation with a physician to review the results and receive both lifestyle and medication recommendations. Approximately 6 years later, the patients were queried to determine if seeing the CAC scan results, along with the physician counseling, was associated with riskreducing behavioral changes.

\section{Materials and methods}

\section{Subjects}

Chest EBCT scans were performed on asymptomatic patients from October 1999 to May 2002 at a universityaffiliated disease prevention center in San Diego, CA to examine the extent of atherosclerotic calcification in the coronary arteries. This clinical population of participants was either physician or self-referred as a supplement to their preventive health care. Prior studies based on data from this cohort have been published (Allison et al. 2004, 2006, 2007). Patients with known coronary heart disease or who had a history of coronary heart disease related surgery were excluded from the study.

EBCT scans were performed at the first clinic visit (baseline), and all participants completed a detailed health history questionnaire that collected information on demographics, diabetes, hypertension, smoking, alcohol consumption, diet, exercise, and family history of coronary heart disease at that time. Blood pressure was obtained by automated oscillometry after the patient rested for $5 \mathrm{~min}$ in a seated position. Body mass index (BMI), body fat percentage, total cholesterol, high density lipoproteins (HDL), low density lipoproteins, triglycerides (serum cholesterol indices), and glucose were also measured during this baseline clinic visit.
Laboratory

All patients underwent serum lipid analysis using the Cholestech LDX system (Cholestech, Hayward, California). Blood specimens were obtained by fingerstick with the subject in the seated position using a $35 \mu \mathrm{l}$ lithium heparincoated capillary tube. BMI was calculated with the patient clothed but shoe-less and expressed in $\mathrm{kg} / \mathrm{m}^{2}$. Body fat was measured using bioimpedence on the Omron HBF-300 body fat analyzer (Omron, Schaumburg, Illinois).

\section{Imaging}

An Imatron C-150 (General Electric, San Francisco, California) was utilized to perform a single scan to obtain images of each patient's heart. The 100-ms scan time proceeded down from the level of the carina to the level of the diaphragm. Approximately 40-45 contiguous slices of each participant's heart were obtained, each of which were $3 \mathrm{~mm}$ thick. Cardiac tomographic imaging was electrocardiographically triggered at 40 or $65 \%$ of the $\mathrm{R}-\mathrm{R}$ interval, depending on the patient's heart rate. Imaging of the heart was conducted during one breath hold at one-halfmaximal inspiration. The coronary vascular bed consisted of the left circumflex, left anterior descending, left main and right coronary arteries.

Coronary calcification was defined as a plaque area $=$ $1.00 \mathrm{~mm}^{2}$ ( $\geq 3$ pixels) with a density of $\geq 130$ Hounsfield units (HU). Quantitative measures of calcium scores were determined according to the technique explained by Agatston et al. (1990); this calcium scoring was performed by either a computed tomography technician or physician trained in the methodology outlined above. This method has been previously described in detail (Allison et al. 2007).

\section{Physician consultation}

The patients spent approximately 15-30 min with a physician who reviewed the results of the EBCT scan, showed the patient his/her EBCT images, discussed the risk factors associated with $\mathrm{CAC}$, and made recommendations for risk reduction based on the patient's CAC score. Patients were made aware that CAC identifies underlying coronary atherosclerosis and is associated with incident heart disease. The recommendations for risk reduction included nutritional advice, exercise suggestions, and smoking cessation recommendations (if pertinent).

Behavioral assessment

An average of $6 \pm 1$ years (range 3-9 years) after the baseline clinic visit, patients completed a mailed follow-up 
survey that inquired about health behavior changes after the EBCT scan and physician consultation. Specific questions posed included whether, since the coronary artery scan and physician consultation, the patient had decreased or stopped smoking cigarettes if they had been smoking at the time of the scan, started exercising, increased the amount of exercise, changed the type of exercise they used to perform, changed their dietary habits, or changed their use of alcohol. The University of California at San Diego's Human Research Protection Program approved the study protocol, and the requirement for informed consent was waived by this group.

\section{Statistical analysis}

Hypertension was defined either by self-report of physician-diagnosed hypertension and current use of a prescription antihypertensive, or as a diastolic blood pressure or systolic blood pressure $\geq 90$ or $\geq 140 \mathrm{~mm} \mathrm{Hg}$, respectively (Allison et al. 2007). Diabetes was defined either by self-report of physician-diagnosed diabetes and current use of antiglycemic medication, or a blood glucose $>200 \mathrm{mg} / \mathrm{dl}$ ("Diagnosis and classification of diabetes mellitus", 2009). Dyslipidemia was defined either by total cholesterol to HDL ratio $>5$, or by self-report of current use of prescription cholesterol lowering medications (Natarajan et al. 2003). Participants were grouped into either never, former, or current smokers.

The outcome variables for this study were 5 different health behavior changes potentially made after receiving EBCT scan results and the physician consultation: start exercising, change diet, increase exercise, change type of exercise, and change alcohol intake. The primary predictor variables were presence and extent of CAC, with covariates of age, gender, premature sibling and parent heart disease, hypertension, dyslipidemia, BMI, diabetes, and ethnicity. The extent of CAC, age, and BMI were analyzed as continuous variables, and presented as mean values $\pm \mathrm{SD}$; the remaining variables were dichotomized and presented as numbers (percent).

The CAC scores were both log transformed in order to normalize the distribution of this variable, and dichotomized (i.e. presence versus absence of calcification) for use in logistic regression. Several one-way between-groups analyses of covariance (ANCOVA) were conducted, adjusted for age and gender, to investigate multivariable associations between the primary predictor variables and outcome variables. Established risk factors for prevalent calcification that are associated with the outcome variables were included in Model 2 described below.

The potential impact of the presence and extent of CAC on the likelihood that participants would report changes in lifestyle behaviors was explored with two binary logistic regression models. These models were first adjusted for only age and gender (Model 1). Next, the models were additionally adjusted for accepted CVD risk factors and covariates found to be significant $(P \leq 0.15)$ by the ANCOVA analysis (Model 2). In these analyses, potential covariates included age, gender, BMI, hypertension, dyslipidemia, diabetes, and parent and sibling history of premature heart disease. The Hosmer-Lemeshow goodness-of-fit test was utilized to assess the logistic regression models. This study specified a significance level of 0.05 or below (2-tailed) in the multivariable models. All statistical analyses were conducted using SPSS version 16.0 statistical package.

\section{Results}

After excluding those individuals who had a history of coronary procedure, 510 participants returned the mailed questionnaire. Characteristics of this sample are presented in Table 1. Patients were an average of 64 years old (SD 9.69; range 38-94) and women comprised $38.2 \%$ of the cohort. The average BMI in this population was 26.6 (SD 4.08; range 18-41), and 41.8\% were considered overweight based on BMI. Among these patients, $21.4 \%$ had a parent with a history of premature heart disease; $2.8 \%$ had diabetes; $43.9 \%$ had hypertension; $35.1 \%$ had dyslipidemia; $45.3 \%$ had smoked at some point; $4.1 \%$ were smoking at the time of the scan; and $80.8 \%$ drank alcohol before the scan. Two-hundred and ninety-five participants (58\%) were found to have CAC. The mean and median coronary calcium scores were 202.8 and 8.5, respectively (range $0-5,117)$. The average duration between the baseline clinic visit and completion of the survey was $6 \pm 1$ years (range 3-10).

Subsequent to receiving results of the EBCT scan and physician consultation, $9.6 \%$ of patients reported that they started exercising; $15.9 \%$ said they increased amount of exercise; $11.0 \%$ said they changed the type of exercise they were performing; $27.3 \%$ said they changed their dietary habits; $6.3 \%$ reported that they changed their use of alcohol; and of the $21(4.12 \%)$ participants who reported smoking at the time of the scan, 3 (14.29\% of those smokers) reported decreasing or stopping smoking. Among the 32 patients who reported a change in their use of alcohol, $28.1 \%(\mathrm{~N}=9)$ reported an increase in consumption; $43.8 \%(\mathrm{~N}=14)$ said they decreased consumption; and $62.5 \%(\mathrm{~N}=20)$ reported an increase in red wine consumption.

The characteristics of the cohort stratified by the presence or absence of CAC are provided in Table 2. Those with any CAC were significantly older (66.7 vs. 61.5, $P<0.01$ ), with a significantly higher proportion of men 
Table 1 Descriptive Statistics

\begin{tabular}{|c|c|}
\hline Characteristics & Mean (continuous) or percent (categorical) \\
\hline Age (years), mean (SD) (At Cycle I Questionnaire) & $64.48(10.47)$ \\
\hline Female, n (\%) & $195(38.20 \%)$ \\
\hline \multicolumn{2}{|l|}{ Ethnicity, n (\%) } \\
\hline American Indian/Alaska Native & $2(.397 \%)$ \\
\hline Asian & $7(1.39 \%)$ \\
\hline Black/African American & $1(.198 \%)$ \\
\hline Native Hawaiian/Pacific Islander & $0(0 \%)$ \\
\hline White & $488(95.7 \%)$ \\
\hline Other & $6(1.19 \%)$ \\
\hline BMI $\left(\mathrm{kg} / \mathrm{m}^{2}\right)$, mean & $26.61(\mathrm{SD}=4.084 ;$ Range $=18-41)$ \\
\hline Parent heart disease before $55, \mathrm{n}(\%)$ & $108(21.4 \%)$ \\
\hline Sibling heart disease before $55, \mathrm{n}(\%)$ & $43(8.4 \%)$ \\
\hline Coronary artery calcium, mean & $\begin{array}{l}202.84(\mathrm{SD}=523.772 ; \text { Range }=0-5,117 ; \\
\quad \text { Median }=8.51)\end{array}$ \\
\hline Have calcium in heart $(\mathrm{CAC}>0), \mathrm{n}(\%)$ & $295(57.8 \%)$ \\
\hline Diabetes, n (\%) & $14(2.8 \%)$ \\
\hline Hypertension, n (\%) & $224(43.9 \%)$ \\
\hline Dyslipidemia, n (\%) & $179(35.1 \%)$ \\
\hline Ever smoker, n (\%) & $231(45.30 \%)$ \\
\hline Smoked at time of scan, $\mathrm{n}(\%)$ & $21(4.12 \%)$ \\
\hline Decrease/stop smoking b/c of scan, n (\%) & $3(2.36 \%)$ \\
\hline Drank alcohol B4 scan, n (\%) & $412(80.8 \%)$ \\
\hline Changed alcohol use b/c of scan results, $\mathrm{n}(\%)$ & $32(6.3 \%)$ \\
\hline Increased consumption & $9(28.1 \%)$ \\
\hline Decreased consumption & $14(43.8 \%)$ \\
\hline Increased red wine consumption & $20(62.5 \%)$ \\
\hline Changed diet after scan, $\mathrm{n}(\%)$ & $139(27.3 \%)$ \\
\hline Started exercising after scan, $\mathrm{n}(\%)$ & $49(9.6 \%)$ \\
\hline Increased exercise after scan, n (\%) & $81(15.9 \%)$ \\
\hline Changed type of exercise after scan, n (\%) & $56(11.0 \%)$ \\
\hline
\end{tabular}

Table 2 Cohort Characteristics Stratified by the Presence/ Absence of Coronary Artery Calcium (ANCOVA)

$B M I$ body mass index, $C A C$ coronary artery calcium

a Adjusted for gender

b Adjusted for age

c Adjusted for age and gender

\begin{tabular}{|c|c|c|c|}
\hline Variable & $\mathrm{CAC}>0(\mathrm{~N}=295)$ & $\mathrm{CAC}=0(\mathrm{~N}=215)$ & $P$ value \\
\hline Age (years), mean $(S D)^{a}$ & $66.69(10.18)$ & $61.48(11.07)$ & $<0.01$ \\
\hline Female, $\mathrm{n}(\%)^{\mathrm{b}}$ & $85(29 \%)$ & $110(51 \%)$ & $<0.01$ \\
\hline BMI $\left(\mathrm{kg} / \mathrm{m}^{2}\right)$, mean $(\mathrm{SD})^{\mathrm{c}}$ & $26.70(3.831)$ & $26.49(4.412)$ & 0.511 \\
\hline Parent heart disease before $55, \mathrm{n}(\%)^{\mathrm{c}}$ & $65(22 \%)$ & $44(20 \%)$ & 0.106 \\
\hline Sibling heart disease before $55, \mathrm{n}(\%)^{\mathrm{c}}$ & $28(9 \%)$ & $15(7 \%)$ & 0.172 \\
\hline Coronary artery calcium, mean ${ }^{c}$ & $\begin{array}{c}350.67(\mathrm{SD}=650.34 \\
\quad \text { Median }=94.63)\end{array}$ & $\begin{array}{l}0(\mathrm{SD}=0 ; \\
\quad \text { Median }=0)\end{array}$ & $<.01$ \\
\hline Diabetic, $\mathrm{n}(\%)^{\mathrm{c}}$ & $13(5.1 \%)$ & $1(0.5 \%)$ & 0.016 \\
\hline Hypertension, $\mathrm{n}(\%)^{\mathrm{c}}$ & $155(37.36 \%)$ & $69(20.71 \%)$ & $<0.01$ \\
\hline Dyslipidemia, $\mathrm{n}(\%)^{\mathrm{c}}$ & $114(38.64 \%)$ & $65(30.23 \%)$ & 0.180 \\
\hline Smoke at time of $\operatorname{scan}^{c}$ & $12(9 \%)$ & $9(10 \%)$ & 0.671 \\
\hline Drank alcohol before $\operatorname{scan}^{\mathrm{c}}$ & $236(81 \%)$ & $176(83 \%)$ & 0.312 \\
\hline Changed alcohol use after $\operatorname{scan}^{c}$ & $24(8 \%)$ & $8(4 \%)$ & $<0.01$ \\
\hline Started exercising after $\operatorname{scan}^{\mathrm{c}}$ & $35(12 \%)$ & $14(7 \%)$ & 0.04 \\
\hline Increased exercise after $\operatorname{scan}^{c}$ & $55(19 \%)$ & $26(12 \%)$ & $<0.01$ \\
\hline Changed exercise type after $\operatorname{scan}^{c}$ & $36(13 \%)$ & $20(10 \%)$ & 0.164 \\
\hline Changed diet after $\operatorname{scan}^{\mathrm{c}}$ & $95(33 \%)$ & $44(21 \%)$ & $<0.01$ \\
\hline
\end{tabular}


(71.0 vs. $29.0 \%, P<0.01$ ). After adjusting for age and gender, participants with a CAC score $>0$ had a significantly higher prevalence of hypertension (37.4 vs. $20.7 \%$, $P<0.01)$ and diabetes $(5.1 \%$ vs. $0.5 \%, P=0.02)$, and were more likely to change alcohol intake ( 8.0 vs. $4.0 \%$, $P<0.01$ ), start exercising (12.0 vs. $7.0 \%, P=0.04)$, increase their exercise $(19.0$ vs. $12.0 \%, P<0.01)$, and change their diet $(33.0$ vs. $21.0 \%, P<0.01)$. Figure 1 shows the percentage of patients who changed these health behaviors according to presence or absence of CAC, and Fig. 2 illustrates the median CAC score by health behavior.

When controlling only for age and gender (Model 1), the odds of participants reporting that they started exercising, changed their diet, increased their exercise, changed type of exercise, and changed their alcohol consumption after the scan and physician consultation were $2.04(P=0.04)$, $1.99(P<0.01), 2.15(P<0.01), 1.53(P=0.17)$, and $3.00(P=0.02)$ times higher, respectively, for those with any CAC compared to those without CAC. Using a 1-unit increment in the log transformed CAC score, and with adjustment for age and gender (Model 1), the odds of participants reporting that they started exercising, changed their diet, increased their exercise, changed type of

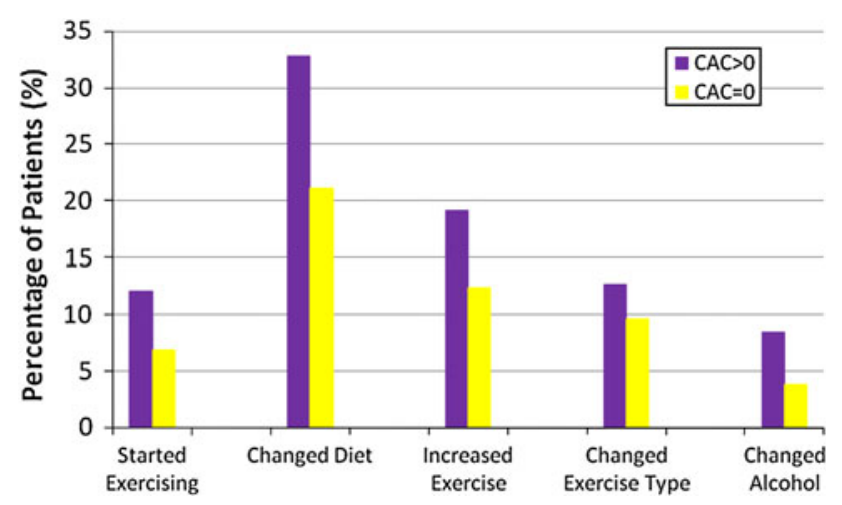

Fig. 1 Percentage of patients who changed health behaviours, according to presence or absence of CAC



Fig. 2 Median coronary artery calcium score by health behaviour exercise, and changed their use of alcohol after the scan and physician consultation were $1.43(P=0.01), 1.39$ $(P<0.01), 1.43(P<0.01), 1.24(P=0.11)$, and 1.36 $(P=0.07)$ times higher, respectively.

Results from the separate ANCOVAs, which were adjusted for age and gender, are shown in Table 3. These results along with the results from the ANCOVAs performed with the cohort stratified by the presence or absence of CAC, determined which covariates were included in Model 2. When all significant covariates $(P \leq 0.15)$ were controlled for (Model 2), the odds of participants reporting that they started exercising, changed their diet, increased their exercise, changed type of exercise, and changed their alcohol consumption after the scan and physician consultation were $1.52(P=0.26), \quad 1.74 \quad(P=0.02), \quad 1.78$ $(P=0.06), 1.27(P=0.48), 3.05(P=0.03)$ times higher, respectively, for those with any CAC compared to those without CAC. In this same model, but using a 1-unit increment in the log transformed CAC score, the odds of participants reporting that they started exercising, changed their diet, increased their exercise, changed type of exercise, and changed their use of alcohol after the scan and physician consultation were $1.26(P=0.13), 1.40$ $(P<0.01), 1.35(P=0.02), 1.21(P=0.19)$, and 1.46 $(P=0.05)$ times higher, respectively. These odds ratios are shown in Table 4.

\section{Discussion}

In this longitudinal study of 510 asymptomatic men and women, the effects of EBCT scan visualization, knowledge of CAC measurement, and brief physician consultation were significantly associated with changes in health related behaviors. Specifically, patients with EBCT scans that revealed CAC were more likely to begin exercising, increase their exercise, change their diet, and change their alcohol consumption.

Perhaps patients' perceived threat of atherosclerotic disease was altered after visualizing the EBCT scan and obtaining results and a greater understanding of the disease; the "teachable moment" that occurs during visualization of coronary plaque burden on the EBCT scan may be responsible for beneficial lifestyle changes. The motivation may be due to a change in patients' perception of health status or disease threat, as has been reported in previous studies (Kalia et al. 2006; Wong et al. 1996).

Motivation for adopting healthy behaviors and modifying harmful cardiovascular risk factors is multifactorial and differs for each individual. Many models of health behavior change integrate perceived vulnerability as a catalyst for health-related behavior change. There are numerous modifiable risk factors for atherosclerosis including physical 
Table 3 Results from separate analyses of covariance (ANCOVA) examining multiple characteristics as indicators of probability for health behavior change at follow-up $(n=510)$

\begin{tabular}{|c|c|c|c|c|c|c|c|c|c|c|}
\hline \multirow[t]{2}{*}{ Characteristics } & \multicolumn{3}{|c|}{ Started exercising } & \multicolumn{4}{|c|}{ Increased exercise } & \multicolumn{3}{|c|}{ Changed exercise type } \\
\hline & $\begin{array}{l}\text { Yes } \\
(\mathrm{N}=49)\end{array}$ & $\begin{array}{l}\text { No } \\
(\mathrm{N}=447)\end{array}$ & $P$ value & $\begin{array}{l}\text { Yes } \\
(\mathrm{N}=81)\end{array}$ & \multicolumn{2}{|c|}{$\begin{array}{l}\text { No } \\
(\mathrm{N}=416)\end{array}$} & $P$ value & $\begin{array}{l}\text { Yes } \\
(\mathrm{N}=56)\end{array}$ & $\begin{array}{l}\text { No } \\
(\mathrm{N}=437)\end{array}$ & $P$ value \\
\hline Age (years), mean $(\mathrm{SD})^{\mathrm{a}}$ & $\begin{array}{l}64.71 \\
\quad(10.84)\end{array}$ & $\begin{array}{l}64.36 \\
(10.92)\end{array}$ & 0.15 & $\begin{array}{l}61.41 \\
\quad(11.30)\end{array}$ & \multicolumn{2}{|c|}{$\begin{array}{l}64.85 \\
\quad(10.69)\end{array}$} & 0.41 & $\begin{array}{l}62.66 \\
\quad(12.79)\end{array}$ & $\begin{array}{l}64.55 \\
\quad(10.66)\end{array}$ & 0.20 \\
\hline Female, $\mathrm{n}(\%)^{\mathrm{b}}$ & $20(40.82)$ & $169(37.81)$ & 0.67 & 33 (40.74) & \multicolumn{2}{|c|}{$157(37.74)$} & 0.75 & $21(37.0)$ & $168(38.0)$ & 0.82 \\
\hline BMI $\left(\mathrm{kg} / \mathrm{m}^{2}\right)$, mean $^{\mathrm{c}}$ & 27.57 & 26.51 & 0.29 & 26.80 & \multicolumn{2}{|c|}{26.61} & 0.13 & 26.41 & 26.68 & 0.62 \\
\hline $\begin{array}{l}\text { Parent heart disease } \\
\quad \text { before age } 55, \mathrm{n}(\%)^{\mathrm{c}}\end{array}$ & $11(22.49)$ & $91(20.36)$ & 0.749 & $18(22.22)$ & \multicolumn{2}{|c|}{$87(21)$} & 0.97 & $8(14)$ & $93(21)$ & 0.18 \\
\hline $\begin{array}{l}\text { Sibling heart disease } \\
\quad \text { before age } 55, \mathrm{n}(\%)^{\mathrm{c}}\end{array}$ & $8(16.33)$ & $34(7.61)$ & 0.04 & $10(12.0)$ & \multicolumn{2}{|c|}{$32(8.0)$} & 0.18 & $5(9.0)$ & $36(8.0)$ & 0.87 \\
\hline $\begin{array}{l}\text { Coronary artery calcium, } \\
\text { mean }(\mathrm{SD})^{\mathrm{c}}\end{array}$ & $\begin{array}{l}338.90 \\
\quad(823.97)\end{array}$ & $\begin{array}{l}190.43 \\
(485.23)\end{array}$ & $<0.01$ & $\begin{array}{l}316.07 \\
\quad(785.0)\end{array}$ & \multicolumn{2}{|c|}{$\begin{array}{l}177.82 \\
\quad(457.0)\end{array}$} & $<0.01$ & $\begin{array}{r}390.26 \\
(921)\end{array}$ & $\begin{array}{r}177.03 \\
(445)\end{array}$ & 0.23 \\
\hline $\mathrm{CAC}>0, \mathrm{n}(\%)^{\mathrm{c}}$ & $35(71.43)$ & $255(57.05)$ & 0.04 & $55(67.90)$ & \multicolumn{2}{|c|}{$232(55.77)$} & $<0.01$ & $36(64.29)$ & $248(56.75)$ & 0.16 \\
\hline Diabetes, $\mathrm{n}(\%)^{\mathrm{c}}$ & $3(6.7)$ & $11(2.8)$ & 0.17 & $3(4.0)$ & \multicolumn{2}{|c|}{$11(3.0)$} & 0.595 & $0(0)$ & $14(3.6)$ & 0.20 \\
\hline Hypertension, $\mathrm{n}(\%)^{\mathrm{c}}$ & $34(69.39)$ & $182(40.72)$ & $<0.01$ & $39(48.15)$ & \multicolumn{2}{|c|}{$178(42.79)$} & 0.13 & $28(50.0)$ & $186(42.56)$ & 0.18 \\
\hline Dyslipidemia, $\mathrm{n}(\%)^{\mathrm{c}}$ & $25(51.02)$ & $150(33.56)$ & 0.01 & $46(56.79)$ & 130 & $(31.25)$ & $<0.01$ & $28(50.0)$ & $146(33.41)$ & 0.01 \\
\hline Characteristics & & Change & diet & & & & Chan & ed alcohol & & \\
\hline & & Yes $(\mathrm{N}$ & $=141)$ & No $(\mathrm{N}=3$ & & $P$ value & Yes ( & $\mathrm{v}=32)$ & No $(\mathrm{N}=462)$ & $P$ value \\
\hline Age (years), mean $(\mathrm{SD})^{\mathrm{a}}$ & & 63.38 & 1.95) & $64.67(10.46$ & & 0.856 & 57.88 & $(18.55)$ & $64.84(10.01)$ & $<0.01$ \\
\hline Female, $\mathrm{n}(\%)^{\mathrm{b}}$ & & $48(34.5$ & & $139(38.72)$ & & 0.33 & $7(22$. & & $181(39.0)$ & 0.03 \\
\hline BMI $\left(\mathrm{kg} / \mathrm{m}^{2}\right)$, mean $^{\mathrm{c}}$ & & 26.79 & & 26.56 & & 0.15 & 27.35 & & 26.58 & 0.41 \\
\hline Parent heart disease befor & age $55, \mathrm{n}(\%$ & $29(21)$ & & $75(21)$ & & 0.97 & $2(6.0$ & & $102(22.0)$ & 0.02 \\
\hline Sibling heart disease befor & e age $55, \mathrm{n}(\mathrm{c}$ & $12(8.6 ?$ & & $31(8.64)$ & & 0.99 & $5(12$ & & $37(8.0)$ & 0.14 \\
\hline Coronary artery calcium, & hean $(\mathrm{SD})^{\mathrm{c}}$ & 284.12 & $655.35)$ & $177.40(469$ & 14) & 0.03 & 334.0 & $(610)$ & $183.51(501)$ & 0.04 \\
\hline $\mathrm{CAC}>0, \mathrm{n}(\%)^{\mathrm{c}}$ & & $95(68.3$ & & $195(54.32)$ & & $<0.01$ & $24(7$ & & $260(56.28)$ & $<0.01$ \\
\hline Diabetes, $\mathrm{n}(\%)^{\mathrm{c}}$ & & $6(4.8)$ & & $7(2.2)$ & & 0.18 & $0(0)$ & & $14(3.4)$ & 0.32 \\
\hline Hypertension, $\mathrm{n}(\%)^{\mathrm{c}}$ & & $65(46.7$ & & $154(42.90)$ & & 0.32 & $14(4$ & $.75)$ & $201(43.51)$ & 0.50 \\
\hline Dyslipidemia, $\mathrm{n}(\%)^{\mathrm{c}}$ & & $61(43.8$ & & $113(31.48)$ & & 0.01 & $15(4$ & $.88)$ & $159(34.42)$ & 0.27 \\
\hline
\end{tabular}

$B M I$ body mass index, $C A C$ coronary artery calcium

a Adjusted for gender

b Adjusted for age

c Adjusted for age and gender

inactivity, cigarette smoking, excessive alcohol consumption, high-saturated fat diets, obesity, diabetes, and hypertension (Allison et al. 2007; Allison and Wright 2005; Third Report of the National Cholesterol Education Program (NCEP) Expert Panel on Detection, Evaluation, and Treatment of High Blood Cholesterol in Adults (Adult Treatment Panel III) final report 2002). Several health behaviors and lifestyle factors such as exercise, dietary intake, smoking, and alcohol consumption are associated with the above mentioned modifiable risk factors. In fact, low-fat vegetarian diets have been shown in several studies to significantly reduce or have a reversal effect on coronary atherosclerosis development (Barnard et al. 2009; Esselstyn 1999; Ornish et al. 1998). Showing patients their EBCT
CAC results was an apparently successful motivating factor.

The current study lends further support for the five previously mentioned studies showing either increased medication compliance or beneficial behavioral change following coronary calcium screening (Kalia et al. 2006; Orakzai et al. 2008; Wong et al. 1996; LaBounty et al. 2009; Taylor et al. 2008). Yet it contradicts the few studies that have not shown healthy behavior changes following CT scans for CAC screening (O'Malley et al. 2003). For example, O'Malley et al. (2003) found that CAC screening and knowledge of electron beam tomography results did not significantly motivate patients to change modifiable cardiovascular disease risk factors. However, this study had 
Table 4 Binary logistic regression models (Odds ratios (95\% confidence intervals); $P$-values)

\begin{tabular}{|c|c|c|c|c|c|c|}
\hline \multirow[t]{2}{*}{ Variables } & \multicolumn{2}{|l|}{ Started exercising } & \multicolumn{2}{|l|}{ Increased exercise } & \multicolumn{2}{|c|}{ Changed exercise type } \\
\hline & Model 1 & Model 2 & Model 1 & Model 2 & Model 1 & Model 2 \\
\hline CAC (Yes/No) & $\begin{array}{l}2.04(1.03,4.02) \\
P=.04\end{array}$ & $\begin{array}{l}1.52(.73,3.16) \\
P=.26\end{array}$ & $\begin{array}{l}2.15(1.25,3.69) \\
P<.01\end{array}$ & $\begin{array}{l}1.78(.99,3.20) \\
P=.055\end{array}$ & $\begin{array}{l}1.53(.83,2.80) \\
P=.17\end{array}$ & $\begin{array}{l}1.27(.65,2.48) \\
P=.48\end{array}$ \\
\hline $\begin{array}{l}\text { CAC (Continuous -log } \\
\quad \text { transformed) }\end{array}$ & $\begin{array}{l}1.43(1.08,1.89) \\
P=.01\end{array}$ & $\begin{array}{l}1.26(.93,1.72) \\
P=.13\end{array}$ & $\begin{array}{l}1.43(1.13,1.80) \\
P<.01\end{array}$ & $\begin{array}{l}1.35(1.05,1.74) \\
P=.02\end{array}$ & $\begin{array}{l}1.24(.95,1.61) \\
P=.11\end{array}$ & $\begin{array}{l}1.21(.91,1.62) \\
P=.19\end{array}$ \\
\hline \multirow[t]{2}{*}{ Variables } & \multicolumn{3}{|c|}{ Changed diet } & \multicolumn{3}{|c|}{ Changed alcohol use } \\
\hline & \multicolumn{2}{|l|}{ Model 1} & Model 2 & \multicolumn{2}{|l|}{ Model 1} & Model 2 \\
\hline CAC (Yes/No) & \multicolumn{2}{|c|}{$\begin{array}{l}1.99(1.29,3.09) \\
P<.01\end{array}$} & $\begin{array}{l}1.74(1.08,2.81) \\
P=.02\end{array}$ & \multicolumn{2}{|c|}{$\begin{array}{l}3.00(1.23,7.32) \\
P=.02\end{array}$} & $\begin{array}{l}3.05(1.12,8.35) \\
P=.03\end{array}$ \\
\hline $\begin{array}{l}\text { CAC (Continuous-log } \\
\text { transformed) }\end{array}$ & \multicolumn{2}{|c|}{$\begin{array}{l}1.39(1.15,1.67) \\
P<.01\end{array}$} & $\begin{array}{l}1.40(1.13,1.73) \\
P<.01\end{array}$ & \multicolumn{2}{|c|}{$\begin{array}{l}1.36(.97,1.91) \\
P=.07\end{array}$} & $\begin{array}{l}1.46(.99,2.15) \\
P=.05\end{array}$ \\
\hline
\end{tabular}

Model $1=$ primary predictor variables + age + gender

Model 2 = Model $1+$ significant covariates [BMI, Dyslipidemia, Diabetes, Hypertension, Parent Heart Disease, Sibling Heart Disease]

several limitations, such as a low prevalence of modifiable risk factors and coronary calcification among participants, which may have insufficiently demonstrated behavior change since disease is presumably the motivating factor (O'Malley et al. 2003). The first study to investigate the effects of CAC screening via EBCT on cardiovascular riskreducing behaviors found increases in several of these behaviors to be associated with the amount of CAC, but CAC was not related to changes in physical activity or tobacco use (Wong et al. 1996). Also, in a study involving 144 asymptomatic smokers self-referred for EBCT, there was no relationship between the presence of CAC and smoking behavior changes or cessation (O'Malley et al. 2002). It is important to note that the patients in the current study received only a brief physician consultation for behavior modification. Longer and more structured advice may have had a greater effect on health behavior change.

\section{Study limitations}

This study has several limitations. First, generalizability of results may be limited due to the self-referred patients, who may not comprise a representative sample of the population. These patients are likely to be more conscious of health related matters and from higher socioeconomic status, thus perhaps engaging in more routine health prevention and improvement than the general population. Also, these patients were predominantly Caucasian, which may hinder applicability of the results to other populations. Second, these participants were free of clinical cardiovascular disease. These issues could have led to an underestimation of the affects of established cardiovascular risk factors on CAC. Third, this study lacked a true control group, and was observational in nature. Fourth, self-reported behavior changes were subjective, non-quantitative, and specifics pertaining to changes and increases in exercise duration were not reported, thereby perhaps limiting the ability to precisely quantify effects. Research has shown that selfreport of prescription compliance and involvement in healthy behaviors tends to be overestimated, and often suffers from recall bias (Liu et al. 2001; Straka et al. 1997). Fifth, it is unknown how long health behavior changes are sustained following screening for cardiovascular disease risk factors, but some evidence shows these changes diminish over time. Because there was an average of 6 years between baseline EBCT scan and the follow-up survey, many patients may have initially adopted beneficial lifestyle behaviors, but after 6 years these behaviors may have ceased, thereby underestimating the affects of EBCT scan results on motivation. Finally, we carefully controlled for confounders that could have influenced behavior change and risk for cardiovascular disease, but it was not possible to control for all potential confounders, such as patients' motivation.

\section{Conclusion}

In summary, this study suggests that EBCT coronary calcium screening may be significant and useful not only in diagnosing coronary atherosclerosis, but also in motivating beneficial lifestyle behaviors in asymptomatic patients. Hopefully these results will encourage the performance of 
randomized trials to investigate health behavior modifications and adoption of risk-reducing behaviors motivated by EBCT scan results or other cardiovascular screening techniques.

Funding source This research was supported by Award Number T32GM084896 from the National Institute of General Medical Sciences (PI: M. Hovell). The content is solely the responsibility of the authors and does not necessarily represent the official views of the National Institute of General Medical Sciences or the National Institutes of Health.

Open Access This article is distributed under the terms of the Creative Commons Attribution Noncommercial License which permits any noncommercial use, distribution, and reproduction in any medium, provided the original author(s) and source are credited.

\section{References}

Agatston, A. S., Janowitz, W. R., Hildner, F. J., Zusmer, N. R., Viamonte, M., Jr., \& Detrano, R. (1990). Quantification of coronary artery calcium using ultrafast computed tomography. Journal of the American College of Cardiology, 15, 827-832.

Allison, M. A., Cheung, P., Criqui, M. H., Langer, R. D., \& Wright, C. M. (2006). Mitral and aortic annular calcification are highly associated with systemic calcified atherosclerosis. Circulation, $113,861-866$.

Allison, M. A., Criqui, M. H., \& Wright, C. M. (2004). Patterns and risk factors for systemic calcified atherosclerosis. Arteriosclerosis, Thrombosis, and Vascular Biology, 24, 331-336.

Allison, M. A., Lillie, E. O., DiTomasso, D., Wright, C. M., \& Criqui, M. H. (2007). Renal artery calcium is independently associated with hypertension. Journal of the American College of Cardiology, 50, 1578-1583.

Allison, M. A., \& Wright, C. M. (2005). Age and gender are the strongest clinical correlates of prevalent coronary calcification (R1). International Journal of Cardiology, 98, 325-330.

Barnard, N. D., Katcher, H. I., Jenkins, D. J., Cohen, J., \& TurnerMcGrievy, G. (2009). Vegetarian and vegan diets in type 2 diabetes management. Nutrition Reviews, 67, 255-263.

Detrano, R., Guerci, A. D., Carr, J. J., Bild, D. E., Burke, G., Folsom, A. R., et al. (2008). Coronary calcium as a predictor of coronary events in four racial or ethnic groups. The New England Journal of Medicine, 358, 1336-1345.

Diagnosis and classification of diabetes mellitus. (2009). Diabetes Care, 32 (Supplement 1), S62-S67.

Esselstyn, C. B., Jr. (1999). Updating a 12-year experience with arrest and reversal therapy for coronary heart disease (an overdue requiem for palliative cardiology). The American Journal of Cardiology, 84, 339-341, A338.

Kalia, N. K., Miller, L. G., Nasir, K., Blumenthal, R. S., Agrawal, N., \& Budoff, M. J. (2006). Visualizing coronary calcium is associated with improvements in adherence to statin therapy. Atherosclerosis, 185, 394-399.
Klein, R. J., Proctor, S. E., Boudreault, M. A., \& Turczyn, K. M. (2002). Healthy People 2010 criteria for data suppression. Healthy People 2010 Statistical Notes, 24, 1-12.

LaBounty, T. M., Devereux, R. B., Lin, F. Y., Weinsaft, J. W., \& Min, J. K. (2009). Impact of coronary computed tomographic angiography findings on the medical treatment and control of coronary artery disease and its risk factors. American Journal of Cardiology, 104, 873-877.

Liu, H., Golin, C. E., Miller, L. G., Hays, R. D., Beck, C. K., Sanandaji, S., et al. (2001). A comparison study of multiple measures of adherence to HIV protease inhibitors. Annals of Internal Medicine, 134, 968-977.

Natarajan, S., Glick, H., Criqui, M., Horowitz, D., Lipsitz, S. R., \& Kinosian, B. (2003). Cholesterol measures to identify and treat individuals at risk for coronary heart disease. American Journal of Preventive Medicine, 25, 50-57.

O'Malley, P. G., Feuerstein, I. M., \& Taylor, A. J. (2003). Impact of electron beam tomography, with or without case management, on motivation, behavioral change, and cardiovascular risk profile: A randomized controlled trial. Journal of the American Medical Association, 289, 2215-2223.

O’Malley, P. G., Rupard, E. J., Jones, D. L., Feuerstein, I., Brazaitis, M., \& Taylor, A. J. (2002). Does the diagnosis of coronary calcification with electron beam computed tomography motivate behavioral change in smokers? Military Medicine, 167, 211-214.

Orakzai, R. H., Nasir, K., Orakzai, S. H., Kalia, N., Gopal, A., Musunuru, K., et al. (2008). Effect of patient visualization of coronary calcium by electron beam computed tomography on changes in beneficial lifestyle behaviors. The American Journal of Cardiology, 101, 999-1002.

Ornish, D., Scherwitz, L. W., Billings, J. H., Brown, S. E., Gould, K. L., Merritt, T. A., et al. (1998). Intensive lifestyle changes for reversal of coronary heart disease. Journal of the American Medical Association, 280, 2001-2007.

Straka, R. J., Fish, J. T., Benson, S. R., \& Suh, J. T. (1997). Patient self-reporting of compliance does not correspond with electronic monitoring: An evaluation using isosorbide dinitrate as a model drug. Pharmacotherapy, 17, 126-132.

Taylor, A. J., Bindeman, J., Feuerstein, I., Le, T., Bauer, K., Byrd, C., et al. (2008). Community-based provision of statin and aspirin after the detection of coronary artery calcium within a community-based screening cohort. Journal of the American College of Cardiology, 51, 1337-1341.

Third Report of the National Cholesterol Education Program (NCEP) Expert Panel on Detection, Evaluation, and Treatment of High Blood Cholesterol in Adults (Adult Treatment Panel III) final report. (2002). Circulation, 106, 3143-3421.

Wong, N. D., Detrano, R. C., Diamond, G., Rezayat, C., Mahmoudi, R., Chong, E. C., et al. (1996). Does coronary artery screening by electron beam computed tomography motivate potentially beneficial lifestyle behaviors? The American Journal of Cardiology, 78, 1220-1223.

Yusuf, S., Hawken, S., Ounpuu, S., Dans, T., Avezum, A., Lanas, F., et al. (2004). Effect of potentially modifiable risk factors associated with myocardial infarction in 52 countries (the INTERHEART study): Case-control study. Lancet, 364, 937-952. 